\title{
Vinculaciones religiosas, milicias y cabildo: el linaje Viales Briceño en el partido de Nicoya (1768-1824)
}

\section{Arnaldo Rodríguez Espinoza}

Bachiller en la enseñanza de los Estudios Sociales. Licenciado en Docencia con énfasis en la enseñanza de los Estudios Sociales. Licenciado en Educación Cívica. Máster en Historia. Actualmente es tutor en la Cátedra de Historia, Geografía y Educación Cívica de la UNED. Correo: arnaldo682@gmail.com

\author{
Recibido: Enero 2015 • Aceptado: Febrero 2015
}

\section{RESUMEN}

\begin{abstract}
Este artículo propone un estudio de la participación de la familia Viales Briceño en cuanto a las vinculaciones religiosas, milicias y el cabildo en el proceso de incorporación del partido de Nicoya a Costa Rica. Si bien, dicho tema ha sido estudiado de manera macro, este trabajo explora el papel protagónico que pudo haber tenido una élite local y su primacía al ocupar mayoritariamente los principales puestos políticos del ayuntamiento de Nicoya de 1813 a 1824.
\end{abstract}

Palabras clave: Familia, cofradías, capellanías, milicias y cabildo.

\section{ABSTRACT}

The following article presents a study about the Viales Briceño family's participation in the religious and militia realtions; as well as, the town council relations during the inclusion process of Nicoya to Costa Rica. Despite the fact that this topic has been studied before, this paper explores the leading role that would have had a local elite and their supremacy since they took the majority of political seats at the Town Hall in Nicoya from 1813 to 1824.

Key words: family, brotherhood, chaplaincy, militias, town council

La incorporación del partido de Nicoya el 25 de julio de 1824 significó un hecho histórico de gran relevancia para Costa Rica. Y es que sus vínculos no fueron algo fortuito, ya que por ejemplo, los relaciones comerciales suscitadas entre ambas regiones se remontarían desde el siglo XVII.

En tanto, para 1786 este partido (integrado primeramente por Nicoya, Guanacaste [actual Liberia] y posteriormente por Santa Cruz) fue agregado a la Intendencia de Nicaragua mediante Real Cédula del 23 de diciembre, convirtiéndose en una gobernación menor, en la cual existió la figura del Sub-Delegado del Intendente de Nicaragua (Fernández, 1976: 376). De manera tal, Nicoya estuvo supeditado a Nicaragua de 1786 hasta prácticamente julio de 1824. El pueblo de Santa Cruz, primeramente fue conocido con el nombre de "Paraje de Diriá" desde 1805 hasta que se erigió la primera ermita en 1814, momento en el cual se le asignó el nombre actual. Y fue hasta el 19 de abril de 1824 cuando se creó su ayuntamiento (ANCR, Gobernación 1824:f7) y, Villa Guanacaste, desde 1786 hasta 1834 (Sibaja y Zeleya, 1980: 129). 
Así, una vez que el partido de Nicoya se independiza en 1821 del Imperio Español (ANCR, Municipal, 1821: 18v), decidió por su propia voluntad unirse primero a León en 1821 y, posteriormente a Granada en 1822. Esta condición se mantuvo hasta que, finalmente, una minoría (25 firmantes) decidieron agregarse a Costa Rica, representando al $77 \%$ de su población (mayoría) el 25 de julio de 1824, con excepción de Guanacaste, tal y como se señaló líneas atrás. Aunque, dicho acontecimiento no estuvo exento de tensiones e incertidumbre, puesto que fue más complejo, ya que los intereses de las élites locales de Nicoya, Santa Cruz y de Guanacaste tuvieron prioridad.

Sin embargo, este artículo pretende abordar la participación del linaje Viales Briceño, el cuál se constituiría en una élite claramente definida y partícipe en la incorporación del partido en 1824 (Figura 1), puesto que de los 25 firmantes 11 pertenecían a este abolengo y de 1820 a 1824 tuvieron un peso significativo en el ayuntamiento, como se expondrá posteriormente. Y es que esta prosapia pudo convertirse en una élite destacada y primada sobre las demás en la región y, aunque, no fueron el único grupo de poder (Rodríguez, 2012: 57) el hecho que accedieran a los principales puestos políticos los diferenció de las demás élites locales en Nicoya y Santa Cruz.

Así entonces, en las siguientes líneas se abordarán algunos planteamientos sobre el tema de la familia, así como cuáles fueron los vínculos religiosos de este linaje a través de las cofradías

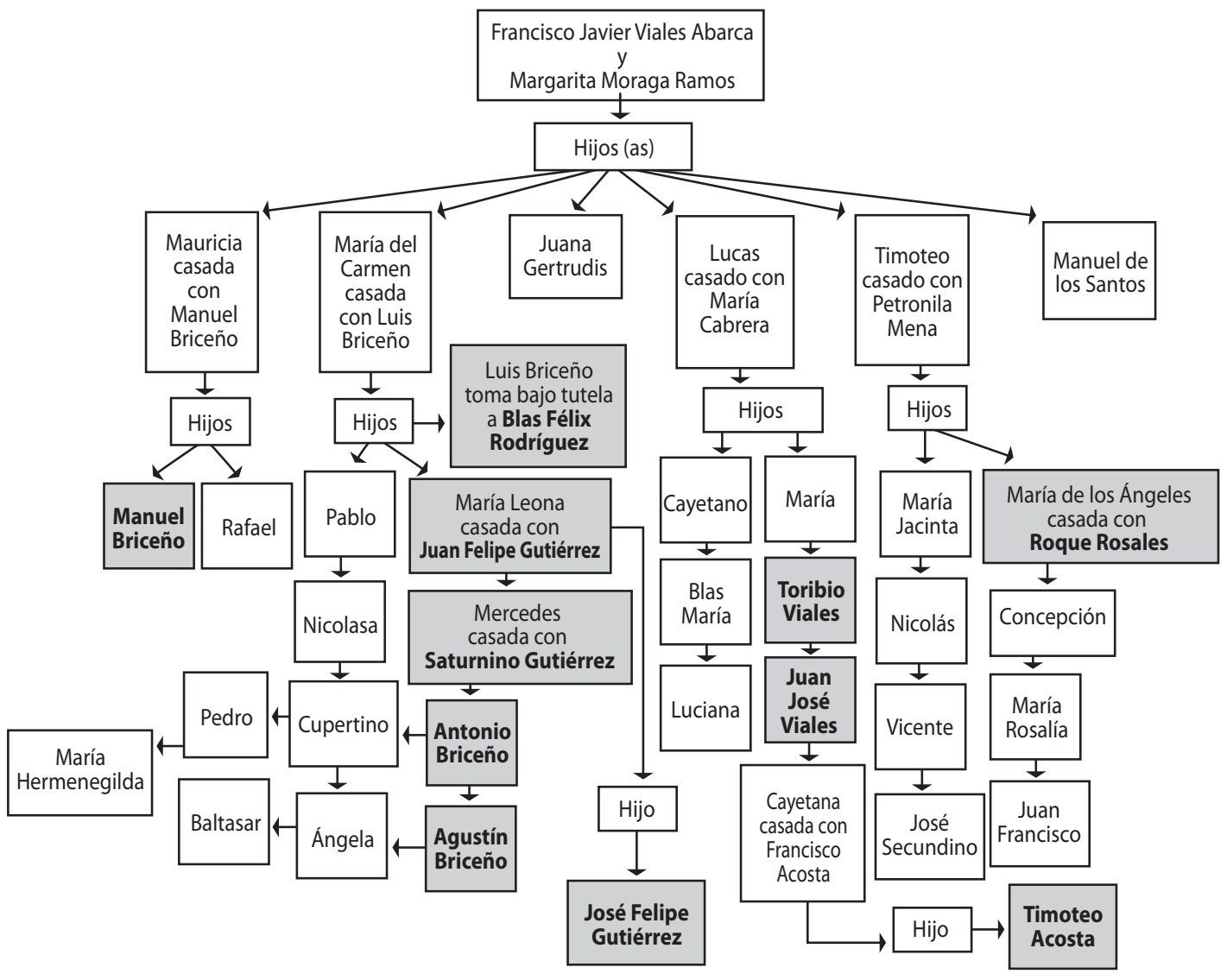

Figura 1. En negrita están representados los firmantes del acta de anexión, pertenecientes al linaje Viales Briceño. Fuente: Índice de Protocolos coloniales de Guanacaste 1750-1850. 
y capellanías, además de su participación en las milicias. Y, finalmente, cuál fue su hegemonía en el cabildo de Nicoya desde prácticamente 1813 hasta 1824, año de la incorporación.

\section{$x$}

En la época colonial, los hilos de poder eran hilos de familia (Madrigal, 2006: 413), ya que la familia se había convertido en una institución sine qua non como estrategia y éxito social durante la colonia. No sólo era importante su capital económico, sino también, su capital social, el cual permitía una vía directa a muchos individuos para iniciar sus carreras políticas.

Así, durante esta época, más que casarse con muchos, era casarse con los mejores (Madrigal, 2006: 384), ya que el prestigio social había que consagrarlo con el tiempo. Por ello, las redes de sociabilidad jugaron un papel fundamental, las cuales "...eran el conjunto permanente o temporal de vínculos de naturaleza diversa que unen a los individuos entre sí", el cual, sería un mecanismo utilizado por la élite, para consagrarse más allá de sus dominios. (Bertrand, 1998: 105), puesto que eran organismos sociales vivos en permanente reconstrucción interna. Es decir, era la manera que en que interactuaban, no sólo a nivel familiar con alianzas fructíferas, sino también, en el plano político y económico, siendo el capital social, su mejor carta de presentación para ocupar puestos políticos.

Esto último puede evidenciarse, en el caso de la familia Viales Briceño, en Nicoya, ya que su poderío económico a través de las haciendas (Rodríguez, 2014: 49-53), no solo les permitió ser una élite representativa, sino que su prestigio incluso se consagró en lo religioso, tema que se abordará a continuación.

\section{$x$}

Las cofradías y capellanías funcionaron como instituciones vitales para dar a conocer el prestigio familiar. Lo anterior, porque si bien la élite tenía claro su posición social, era necesario hacer alarde del poder y el peso de sus linajes, sobre el resto de la población, la cual, evidentemente, quedaba excluida o marginada.

Primeramente, las cofradías eran "congregaciones o hermandades laicas fundadas por los devotos de una advocación religiosa que se reunían con el fin de organizarse para el culto de su devoción" (Velázquez, 2005: 34). Las cofradías organizaban, de esta forma, misas, procesiones y otras festividades, para celebrar la devoción a su santo, para lo que recaudaban fondos y se dotaban de una organización interna. Así pues, las cofradías eran instituciones con vínculos religiosos, aunque no eclesiásticos, porque estaban integradas por laicos y no dependían directamente de la iglesia.

Existieron varias cofradías en el Partido de Nicoya como por ejemplo: Santísimo Sacramento, Nuestra Señora del Viejo y otras dedicadas a la Concepción, a Jesús de Nazareno, al Rosario, a San Blas y a las Benditas Ánimas (Fonseca, 1997: 151) a las cuales pertenecieron algunos miembros de la familia Viales Briceño. Tal fue el caso de los mayordomos Juan Felipe Gutiérrez, Toribio Viales y Saturnino Gutiérrez y, es posible que las hayan utilizado para su propio beneficio económico, a través de los censos u obligaciones. (Cuadro 1)

Los Viales Briceño contrajeron obligaciones económicas crediticias con varias de ellas. Estas pueden haberles servido como fuentes de capital para financiar sus actividades productivas, especialmente, para la obtención de tierras y ganado, ya que las actividades agrícolas se desarrollaban de manera marginal, al menos así quedó reflejado en el censo de 1751 (Fernández, 1888: 481-488) Se sabe que, en las cofradías más ricas, los principales puestos, como el de mayordomo o prioste, eran ocupados por miembros de la élite colonial. Lo que facilitaba el acceso a préstamos de dinero en efectivo con un interés muy bajo (Fonseca, 1998: 35). En la familia Viales Briceño, Francisco Javier Viales, Juan Felipe Gutiérrez, Toribio Viales, Antonio Briceño, Blas María Viales y Saturnino Gutiérrez fueron mayordomos o prioste de cofradía. (Cuadro 1) 


\section{CUADRO 1}

El linaje Viales Briceño y las Cofradías (1805-1848)

\begin{tabular}{|c|c|}
\hline Miembro & Actividad \\
\hline $\begin{array}{l}\text { Juan Felipe Gutiérrez } \\
\text { (Mayordomo de Cofradía Nuestra señora del Viejo, } \\
\text { de Nuestro Amo, de Nuestra Señora del Rosario } \\
\text { y del Señor Sacramentado.) }\end{array}$ & $\begin{array}{l}\text { Arrendamiento de censo que toma Juan Felipe Gutiérrez } \\
\text { a favor de la cofradía de Nuestra Señora del Viejo. (1832) }\end{array}$ \\
\hline $\begin{array}{l}\text { Toribio Viales } \\
\text { (Mayordomo de Cofradía) }\end{array}$ & $\begin{array}{l}\text { Inventario que envía a Toribio Viales, de Nuestra Señora } \\
\text { del Viejo. (1832) }\end{array}$ \\
\hline Roque Rosales & $\begin{array}{l}\text { Escritura de obligación que toma Roque Rosales a favor } \\
\text { de la Cofradía de Nuestra Concepción del Viejo. (1822) } \\
\text { Escritura de obligación que toman Roque Rosales y María } \\
\text { de los Ángeles Viales a favor de la cofradía Nuestra Señora } \\
\text { del Rosario. (1805) }\end{array}$ \\
\hline Agustín Briceño & Arrendatario de la Cofradía del Viejo (1832) \\
\hline Juan José Viales & $\begin{array}{l}\text { Obligación que toma Juan José Viales a favor de la Cofra- } \\
\text { día de Nuestra Señora del Rosario. (1820) } \\
\text { Crédito que toma Juan José Viales a favor de la Cofradía } \\
\text { de San Blas. (1828) } \\
\text { Arrendamiento que toma Juan José Viales a favor de la } \\
\text { Cofradía de Nuestra Señora del Rosario. (1831) } \\
\text { Arrendamiento que toma Juan José Viales a favor de una } \\
\text { Capellanía del Curato. (1838). }\end{array}$ \\
\hline
\end{tabular}

\section{Antonio Briceño}

(Mayordomo de Cofradía de Nuestra

Señora del Viejo)

\section{Saturnino Gutiérrez \\ (Mayordomo de Cofradia de San Blas)}

\section{Blas María Viales}

(Mayordomo de la Cofradía de Nuestra

Señora del viejo)

Cupertino Briceño
Venta que otorga Antonio Briceño de un censo de cofradía a favor de Blas María Viales. (1827)

Entrega al Mayordomo Saturnino Gutiérrez esta Cofradía (San Blas) quedando responsable de todo lo que se le entrega en ella. (1831)

Las cuentas por el mayordomo, Saturnino Gutiérrez, de los Fondos Píos, son devueltas de nuevo por no haberle hecho los reparos señalados. (1834)

Da en arrendamiento a Juan Manuel Núñez, dos caballerías de tierra. (1826)

Escritura de obligación extendida a favor de la Cofradía de Jesús (1832).

Obligación a favor de la Cofradía del Santísimo. (1832)

Fuente: ANCR, Fondo Municipal, Exp 309, 508 y 12708. ANCR, Complementario Colonial, Exp. 2072.

ANCR, Protocolos coloniales Guanacaste, Exp. 205, 212, 227, 228, 232, 243, 248, 250, 274, 310, 383. 
Además, con frecuencia, las cofradías solían realizar préstamos de dinero (llamados en la época "censos" u "obligaciones") o arrendamientos de sus bienes a particulares para financiar sus actividades, por lo que se convirtieron en verdaderas instituciones crediticias en la época (Fonseca, 1998: 85). Estos aspectos fueron aprovechados muy bien por el linaje Viales Briceño, al tener un participación destacada en los principales puestos, pudiendo así beneficiarse y a su vez, mostrando su prestigio a la población.

Por su parte, la fundación de capellanías fue una práctica muy común en la diócesis de Nicaragua y Costa Rica, ya que al menos en el aspecto religioso su vinculación permanecería hasta mitad del siglo XIX. Nicoya no sería la excepción. La capellanía era básicamente una

... fundación eclesiástica instaurada por cláusula testamentaria en la que el testador designaba los bienes que integrarían el capital de esa fundación. Esos bienes se colocaban en arrendamiento y devengaban un rédito del 5\% anual que el capellán cobraba por celebrar, misas rezadas o cantadas en memoria del fundador. (Velázquez, 2005: 28)

Los Viales Briceño fundaron cinco capellanías con sus propios recursos y tomaron en arrendamiento o asumieron la administración de las restantes después de fundadas. (Cuadro 2) Aunque las fuentes son limitadas, el hecho de que existan permite suponer que tenían mucho dinero, ya que "las capellanías fueron un mecanismo más de distribución de la riqueza entre la élite, puesto que sólo los hijos de las familias más acaudaladas podían aspirar al sacerdocio" (Fonseca, 1998: 86).

Para instaurar una capellanía, el fundador empezaba por aportar un capital en plata, cacao o bienes llamado "el principal", el cual se hacía pesar sobre una hacienda, un hato o una casa. En la misma escritura se designaba cuál debía ser el rédito a extraer de este capital, su distribución y si podía redimirse o no. Acto seguido, se nombraba un patrón, a quien correspondía la administración del fondo, y un capellán o capellanes, que generalmente eran parientes de los fundadores, para que recibieran el beneficio de los ramos.

Se conoce como ramos de capellanía a las cantidades determinadas de cuyos réditos se debían pagar las misas por el difunto y para los estudios del sacerdote designado. En algunos casos, los bienes que respaldaban el principal de una capellanía podían arrendarse a inquilinos, quienes quedaban así obligados a entregar los réditos estipulados en una fecha señalada, a mantener en buen estado los bienes y a procurar las mejoras necesarias a estos. Si el principal era redimible, el inquilino podía solicitar la redención al juzgado eclesiástico y otorgar la escritura correspondiente, si no, lo que le quedaba era oblar; es decir, renunciar al inquilinato para que otra persona lo tomara.

Para que estos trámites fueran legales, debían ser avalados por el vicario juez eclesiástico local, o por el síndico general de la orden religiosa correspondiente si la capellanía había sido creada en un convento. Una vez aceptada la redención u oblación de una capellanía, se debía hacer una nueva escritura ante el juez competente. Cuando el inquilino había muerto o habían decrecido los bienes del principal, el inquilinato se concedía por medio de remate al mejor postor. Estos remates se celebraban generalmente a la salida de la misa mayor. Antes de realizar el remate, era necesario informar de él al juez de capellanías de León, quien mandaba fijar un edicto a las puertas de la iglesia parroquial con toda la información de la capellanía para que las personas hicieran la postura con conocimiento de la capellanía a rematar. (Velázquez, 2008: 680-681)

Estos capellanes eran seminaristas que utilizaban los réditos de las capellanías para financiar sus estudios sacerdotales, comprometiéndose a rezar, una vez ordenados, cantidades estipuladas de misas en sufragio del alma de quienes habían financiado sus estudios. Así, las capellanías se convirtieron en el mecanismo por excelencia para costear la educación y el mantenimiento de los hijos y otros parientes allegados, siempre que fueran varones y estudiaran la carrera eclesiástica 


\section{CUADRO 2}

El linaje Briceño Viales y las Capellanías (1772-1844)

Francisco Javier Viales

Francisco Javier Viales,

Manuel José Icavalceta y Juan de Mora
Escritura de fundación de una Capellanía por su alma (1772)

Fundan una Capellanía por el alma de Francisco Rivera. (1772)

Obligación de una Capellanía a favor de su suegro Francisco Javier Viales (1772)

Juan Lucas Viales

Juan Felipe Gutiérrez

(casado con María Leona Briceño)

Manuel Briceño

Santos Viales

Felipe Gutiérrez

( Hijo de María Leona Briceño)

\begin{tabular}{|c|c|}
\hline Vicente Viales & Creación de una capellanía en su nombre (1805) \\
\hline Secundino Viales & Obligación de un principal de Capellanía (1805) \\
\hline Santamaría Viales & Se obliga a favor de un ramo de Capellanía (1806) \\
\hline Concepción Viales, como principal & $\begin{array}{l}\text { Se obliga a favor de una Capellanía que estaba a cago Vicente } \\
\text { Viales (1817) }\end{array}$ \\
\hline Justo Viales & $\begin{array}{l}\text { Reconocimiento de una Capellanía (1827) } \\
\text { Reconocimiento de Capellanía (1833) } \\
\text { Reconocimiento de un principal de Capellanía (1833) } \\
\text { Reconocimiento de una Capellanía (1835) }\end{array}$ \\
\hline
\end{tabular}

Leandro Vega (yerno de Juan José Viales)

Roque Jacinto Rosales

(casado con María de los Ángeles Viales)

Juan José Viales

Cupertino Briceño

Manuel Sobenes
Reconocimiento de una Capellanía (1844)

Arrendamiento de una Capellanía (1838)

Reconocimiento de un principal de Capellanía (1848)

Escritura de fundación de una Capellanía por el alma de Manuel Briceño (1795)

Fundación de Capellanía (1795)

Obligación de una Capellanía (1797)

Fundación de una Capellanía por el alma de Vicente Viales. (1805)

Fianza de una Capellanía

Reconocimiento de una Capellanía (1842)

Dos reconocimientos de una Capellanía (1841)

Reconocimiento de una Capellanía (1840)

Fuente: Protocolos coloniales Guanacaste: Exp. 144, 184, 206, 225, 279, 292, 310, 322, 334, 353, 884, 1190. 
(Velázquez, 2008: 681). Tal y como lo señala la historiadora Carmela Velázquez (2008):

Las capellanías tuvieron varios fines; en primer lugar una ayuda para la salvación del alma ya que por medio de su institución se pensaba que una vez muerto el fundador recibiría el beneficio que otorgaba a su alma la celebración de misas para las que había dejado una suma estipulada en la fundación de la capellanía. Por otro lado se convertían en la principal ayuda económica para el estudio de los parientes que quisieran convertirse en sacerdotes sin la cual no se le permitía el ingreso a los centros de estudio como lo fue el caso de los seminarios. (680-681)

Debido a lo anterior, en esta época no era cualquier individuo el que podría solicitar la fundación de una capellanía, ya que para esto era necesario aportar un capital -sobre el que se extraían los réditos de la capellanía- el cual se establecía generalmente sobre hatos de ganado, tierras y todo tipo de riquezas. Esto presuponía que los fundadores de capellanías debían pertenecer a grupos socio-económicos pudientes, "ya que por lo general eran fundadas por las gentes más ricas, quienes las ordenaban en sus testamentos" (Fonseca, 1997: 237). Este fue, sin duda, el caso de la familia Viales Briceño. Ya que adquirieron obligaciones, reconocieron capellanías, y por su puesto, fundaron varias de ellas. (Rodríguez, 2012: 107), tal y como lo muestra el cuadro 2 . No obstante, también se destacaron por tener rangos militares, lo que les valió un estatus social privilegiado, como se verá seguidamente.

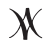

Durante los siglos XVI y XVII las milicias cumplían dos funciones elementales en el nuevo mundo: el reguardo de los territorios de ultramar de la Corona Española y la obtención del prestigio social, puesto que una persona podía valerse de su rango militar para lograr un estatus social reconocido (Marchena, 1992: 134).

Sin embargo, durante el siglo XVIII esas funciones en las milicias cambiarían como consecuencia de la implementación de las reformas borbónicas. Al respecto, señala Juan Marchena (1992):

Las reformas borbónicas, aplicadas al terreno concreto de lo militar en la América de fines del siglo XVIII, transformaron al ejército de América en una institución que no estuvo exclusivamente al servicio del interés defensivo de la Corona española para con sus posesiones de Ultramar, sino que tuvo que asumir la representación de la autoridad real en el Nuevo Mundo, así como respaldar la ejecución de la política de reformas en que estaba empeñada la administración (134).

Un ejemplo de lo mencionado por Marchena, en donde, según el autor, las milicias dejarían de ser claves para el reguardo del territorio se encuentra en la mal llamada Acta de Anexión (Rodríguez, 2015). Esto debido a que uno de los aspectos que los firmantes dejan claro a las autoridades de Costa Rica es la necesidad de que los defiendan ante una eventual invasión por parte de Nicaragua, que se asumía posible ante la decisión de incorporarse a Costa Rica. Lo solicitan de la siguiente manera:

En este estado los jefes militares referidos ysieron precente a esta municipalidad que para no ser perturbados en la libre agregación al estado de Costarrica a que se ha constituido este partido, se hayan absolutamente en la deplorable situación sin fondos $y$ sin armas para sostener sin ser perjudicados pues cabalmente no aparecen más de veinte y seis fusiles ynútiles ... (sic, ANCR, Gobernación, 1824: f12).

En efecto, no existían las condiciones para una defensa del territorio y los rangos militares existentes estaban más en función de un estatus social-político, debido a que se encontraban rangos desde cabos, sargentos, tenientes y hasta el máximo rango militar representado por el coronel, pero cumpliendo una función de control social, dando la posibilidad de asumir una carrera política.

Así, a mediados del siglo XVIII no era casual que muchos individuos mostraran algunos cargos y rangos militares como consecuencia de las implementaciones de las reformas borbónicas, más aún, que los hijos de los peninsulares, tuvieran la 
oportunidad de mantener la tradición y prestigio familiar en su pertenencia a las milicias. Por otra parte, las élites locales, tuvieron acceso a la obtención de rangos militares, obteniendo un mayor prestigio. Así mismo, la familia Viales Briceño no fue la excepción (Cuadro 3).

\section{CUADRO 3}

\begin{tabular}{ll}
\hline Juan José Viales & Coronel \\
Francisco Javier Viales & Teniente de Milicias \\
Luis Briceño & Teniente \\
Timoteo Viales & Teniente \\
Manuel Briceño & Sargento \\
Pedro Briceño & Sargento \\
Antonio Briceño & Sargento \\
Santos Viales & Sargento de Caballería \\
Nicolás Santamaría Viales & Sargento \\
Roque Rosales & Sargento \\
Lucas Viales & Capitán \\
Agustín Briceño & Cabo \\
Blas Félix Rodríguez & Cabo \\
\hline
\end{tabular}

Fuentes: Elaboración propia: pc Guanacaste, Exp, 140, 144, 174, 176 y 188. Gobernación Exp 8845. Hacienda Exp 7888. (Sibaja, Luis Fernando y Zelaya Chester, 1980:144-146). Archivo Nacional de Costa Rica.

En tanto, resulta oportuno señalar que"[1] as milicias disciplinadas del Reino de Guatemala ayudaron a la Corona...a ganar la lealtad de la élite, ofreciéndoles los principales cargos dentro de las milicias, que confieren títulos y honores militares." (Arguedas, 2006: 8). En efecto, las milicias no solo eran instituciones de defensa, sino que constituían espacios para tener prestigio social y beneficiarse de un aparato político como el cabildo. Puesto que, por un lado, las élites legitimaban su condición aventajada sobre los demás grupos sociales y por otro, la monarquía se garantizaba, una representación y ejecución de sus políticas, a través de sus "vasallos más leales" (élite local).

Según Eduardo Madrigal, "el cabildo era el lugar donde se concentraban las compañías de milicias para hacer las revistas y alardes" (Madrigal, 2006: 250). Así, la relación entre el cabildo y las milicias se evidencia en que algunos miembros de los cabildos, también, eran militares, lo que muestra la relación intrínseca entre los puestos políticos y las milicias (Madrigal, 2006: 239-261).

Lo anterior, no fue ajeno en el cabildo de Nicoya, ya que su acceso estaba predispuesto a unos pocos individuos, dotados entre otras cosas, por su prestigio militar donde el linaje Viales Briceño tuvo una destacada participación. En tanto, no era casualidad que de los 25 firmantes del acta de incorporación, 9 tuvieran rango militar: Coronel Juan José Viales, Sargento ${ }^{1^{\circ}}$ Manuel Briceño, Sargento Antonio Briceño, Sargento ${ }^{2^{\circ}}$ Roque Rosa-

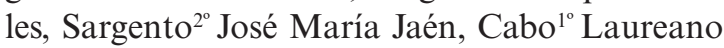
Montes, Cabo ${ }^{1^{\circ}}$ Agustín Briceño, Cabo Blas Félix Rodríguez, Cabo Timoteo Acosta. (ANCR, Gobernación, 1824: f12)

Así entonces, las milicias en el partido de Nicoya durante la segunda mitad del siglo XVIII no cumplieron el objetivo de defensa del territorio, sino que los rangos militares fueron establecidos con la finalidad de proporcionar prestigio social a una élite local, lo que les permitió la participación destacada dentro de la política. Por tanto, es posible que el abolengo Viales Briceño se convirtiera en la representación de las nuevas políticas implementadas a partir de las reformas borbónicas en América, ya que no solo presumían su prestigio a través de sus rangos militares, sino que eran legitimados por la Corona, a través de cargos políticos, representados en la figura del cabildo, como se verá a continuación.

\section{$x$}

Es importante destacar que el linaje Viales Briceño ocuparía los principales puestos del ayuntamiento de Nicoya desde 1813 a 1848 aproximadamente, lo que los convertiría en la élite social más representativa en esa región. (Rodríguez, 2012:141-144).

Por su parte, interesa que en la periferia no se desarrollaran varias familias como élites de poder, lo que sí ocurrió en la zona urbana. Un ejemplo evidente es Cartago, donde el entramado era mucho más complejo, con varias familias, tales como los Bonilla, Alvarado, Peralta, Carazo, 
Prieto, Madriz; entre otros, todos tenían la intención de asumir los principales cargos políticos.

En Nicoya, prácticamente, sólo la red familiar de los Viales Briceño asumió los principales puestos políticos. Es decir, una élite reducida y específica controló la región de Nicoya. Además, esta familia era la más poderosa y representativa en el aspecto político, como se expondrá ulteriormente, ya que asumió los principales puestos del cabildo de 1813 a 1848 aproximadamente, lo que le permitiría desarrollar una red de poder político, así como una amplia red familiar.

Así, la decisión de incorporarse a Costa Rica pudo recaer en una familia poderosa de Nicoya y no en otros linajes de Santa Cruz y Guanacaste, puesto que por un lado, el cabildo de Santa Cruz era de reciente data (abril de 1824), sin olvidar, que prácticamente le otorgaron la decisión final a Nicoya. Y por otro, Guanacaste, decidió seguir vinculada con Nicaragua hasta 1834 según lo acordado en cabildo abierto el 23 de mayo de 1824 (ANCR, Provincial Independiente, 1824, f. $1 v)$. Por eso, este trabajo se enfoca específicamente en Nicoya y la familia que tuvo un papel protagónico en el proceso.

Un aspecto importante es que Nicoya rechazó la invitación hecha por las autoridades de Costa Rica mediante el acta del 4 de julio de 1824 . Sin embargo, dicha postura cambió y el 25 de julio aceptaron la propuesta de incorporarse. Es interesante cómo la opinión de los dirigentes del partido de Nicoya cambió prácticamente en veintiún días. Esto no se debió a lealtades nacionalistas ni a un sentimiento patriótico, ya que no se habían creado aún los estados nacionales (Buska, 2006: 43), por lo que privaron los intereses de las élites regionales.

Así, las élites locales conformarían redes de poder con la clara intención de velar por sus intereses económicos por medio del aparato político-administrativo, como lo fue el cabildo. En Nicoya, destacaría la red de poder familiar representada por el abolengo Viales Briceño

Por consiguiente, para estudiar la funcionalidad y la estructuración política, jurídica y colonial de la América española hay que remitirse, en primera instancia, al cabildo, el cual desde el siglo XVI sería la primera y máxima autoridad del poder local. Así entonces, “...el establecimiento del cabildo era el acto primigenio por medio del cual se fundaba la ciudad" (Madrigal, 2006: 4). Tanto así, que "...el cabildo era la base jurídica de la ciudad, sin la cual no podía ella existir" (Madrigal, 2006: 7)

El cabildo era la forma como los españoles ponían en orden el caos generado por la conquista. Tenía importancia social y política, ya que el surgimiento de esta entidad significó el auge de localidades que permitirían, luego, el establecimiento de otras instancias del gobierno colonial.

Esta institución estaba dividida en dos secciones: la justicia y el regimiento. La primera estaba constituida por los jueces de primera instancia quienes se nombraban año a año. Estos jueces eran los alcaldes ordinarios. La segunda estaba constituida por los regidores, quienes tenían a su cargo la responsabilidad de reunirse periódicamente para tratar asuntos de administración urbana (Madrigal, 2006: 41).

El cabildo de Nicoya se fundó en el siglo XVI y era un "cabildo de indios" que, posteriormente, se convertiría en una institución política de gran relevancia para la región ya que, tres siglos después, fue a través de él que se declaró la incorporación como ayuntamiento constitucional. Además, era la principal institución política donde la élite se veía representada a través del ejercicio de poder.

Pero, ¿cómo se dio el paso de un cabildo de indios a uno constitucional? Todavía durante prácticamente el siglo XVIII, en Nicoya funcionó el cabildo de indios, ya que este territorio seguía siendo corregimiento y/o alcaldía mayor ${ }^{1}$, razón por la cual no tenía relevancia el funcionamiento de un cabildo español, ya que era una jurisdicción basada en una población indígena.

Sin embargo, la realidad distaba del origen de su creación y funcionamiento como

1. Demarcación político-administrativo, integrada exclusivamente por pueblos de indios y bajo autoridad de un alcalde mayor o corregidor. Velásquez: 2005: 6 
corregimiento o alcaldía mayor en el siglo XVI, debido a la hecatombe demográfica suscitada por el encuentro con las huestes conquistadoras. Aun así, para el siglo XVII y XVIII este territorio podía haber sido aun un pueblo de indios o mulatos, pero no de españoles, dada la escasa población europea. Thiel estimaba, con base a un Censo de 1611, que en Nicoya de una población total de 1499 habitantes en 1700, un total de 833 (55,6 $\%$ ) eran mulatos o zambos y $647(43,2 \%)$ eran indios. Solamente 10 se clasificaban como mestizos, y apenas 9 eran españoles. (Edelman, 1998: 56) También, el ingeniero Luis Diez Navarro visitó en 1744 la región de Nicoya y apunta lo siguiente: "Es dicho pueblo de Nicoya donde asiste el Alcalde Mayor y el cura de dicha jurisdicción: es de indios y mulatos y no hay español alguno..." (Cabrera, 1924: 344-346)

Las Cortes de Cádiz vendrían a cambiar drásticamente esta estructura indígena, que, ya de por sí, nunca había tenido validez como entidad política para la Corona Española, porque había nacido como un mecanismo de control y aprovechamiento de la población indígena, que había sido ubicada o distribuida en los llamados "pueblos de indios".

Desde luego, las Cortes de Cádiz permitirían la inserción de mucha gente nueva al crearse ciudades y cabildos que antes no existían, lo que abriría nuevos espacios de poder para el surgimiento de nuevas élites.

Tal como lo señala el historiador Eduardo Madrigal (2012):

... el resultado más sobresaliente de las Cortes de Cádiz, en lo que respecta al escenario político interno de Costa Rica, fue que se dio el título de ciudades a las tres villas nuevas fundadas en el Valle Central en el siglo XVIII, las cuales pasaron a tener ayuntamiento propio. Estos nuevos municipios -los conocidos "ayuntamientos constitucionales"- habrían de tener un papel capital al momento de la Independencia. También los pueblos de indios y otras poblaciones menores - como Esparza, Cañas y Bagaces-obtuvieron la posibilidad de tener ayuntamientos constitucionales, así como de nombrar electores de parroquia y de partido, para escoger diputados a Cortes y a la diputación provincial local. (p. 9).

En junio de 1813, nace el ayuntamiento constitucional en Nicoya para acatar las disposiciones establecidas en la constitución de Cádiz de 1812. Es por ello que, sólo a partir 1813, se encuentran datos del ayuntamiento de Nicoya, debido a que fue en ese año cuando inició su conformación y control por parte de los ciudadanos españoles, algunos de los cuales también tendrían una participación destacada en la incorporación en 1824 . (Rodríguez, 2012: 127)

Lo anterior, debido a que los signatarios del 19 de junio de 1813 serían: Juan Felipe Gutiérrez (quien fue firmante del acta de incorporación), Blas María Viales (quién fue elector del ayuntamiento en 1820 y 1821), Juan José Viales (quien fue elector del ayuntamiento en 1820, 1821, 1823 y procurador síndico en $1823 \mathrm{y}$, finalmente firmante del acta de incorporación en 1824), Pedro Sobenes (quien había sido delegado y subdelegado de Nicoya; su hijo Manuel Sobenes tendría una participación destacada en el ayuntamiento como procurador síndico en 1821 y 1822 , además de ser uno de los firmantes del acta de anexión) y finalmente, Cayetano Morales, quien era esposo de doña María Blas Viales. (ANCR, Pc Guanacaste, 1818; ANCR, Municipal, 1820; ANCR, Municipal, 1821; ANCR, Municipal, 1822; ANCR, Municipal, 1823 y ANCR, Gobernación, 1824) Así, de 1820 a 1824 los Briceño Viales obtuvieron una participación destacada en el ayuntamiento de Nicoya, puesto que representaron el $52.4 \%$ de los electores y el $60 \%$ de los elegidos en el cabildo, tal y como lo evidencia el cuadro 4. Más aún, que el abolengo Viales Briceño participó en el cabildo desde su creación en 1813, ya que varios firmantes serían también signatarios 11 años después en la incorporación.

La influencia de la familia Viales Briceño en el proceso de incorporación del partido de Nicoya pudo haber sido significativa, ya que es posible que su participación en el ámbito económico, social, religioso y político les permitiera tomar esta decisión tan significativa para la región. 
CUADRO 4

Familia Briceño-Viales y su participación en el ayuntamiento de Nicoya 1820-1824

\begin{tabular}{|c|c|c|c|c|}
\hline Elecciones & Electores & $\begin{array}{l}\text { Participación } \\
\text { de la familia } \\
\text { Viales Briceño }\end{array}$ & Elegidos & $\begin{array}{l}\text { Participación } \\
\text { de la familia } \\
\text { Viales Briceño }\end{array}$ \\
\hline 1820 & $\begin{array}{l}9 \text { electores, de los cuales } \\
4 \text { pertenecían a los Viales Briceño. } \\
\text { (Cupertino Briceño, Pablo Briceño, } \\
\text { Juan José Viales y Blas Viales) }\end{array}$ & $44 \%$ & $\begin{array}{l}6 \text { elegidos, de los cuales } 4 \text { per- } \\
\text { tenecían a la familia Viales Bri- } \\
\text { ceño (Antonio Briceño, Manuel } \\
\text { Briceño, Roque Rosales y Cuper- } \\
\text { tino Briceño) }\end{array}$ & $66 \%$ \\
\hline 1821 & $\begin{array}{l}9 \text { electores, de los cuales } 4 \text { perte- } \\
\text { necían a la familia Viales Briceño } \\
\text { (Blas Viales, Juan José Viales, Ra- } \\
\text { fael Briceño Saturnino Gutiérrez) }\end{array}$ & $44 \%$ & $\begin{array}{l}6 \text { elegidos, de los cuales } 4 \text { per- } \\
\text { tenecían a la familia Viales } \\
\text { Briceño (Rafael Briceño, Juan } \\
\text { Francisco Viales, Saturnino Gu- } \\
\text { tiérrez y Roque Rosales) }\end{array}$ & $66 \%$ \\
\hline 1822 & $\begin{array}{l}9 \text { electores, de los cuales } 3 \text { perte- } \\
\text { necían a la familia Viales Briceño } \\
\text { (Antonio Briceño, Saturnino Gutié- } \\
\text { rrez, Cupertino Briceño) }\end{array}$ & $33 \%$ & $\begin{array}{l}4 \text { elegidos, de los cuales } 3 \text { per- } \\
\text { tenecían a la familia Viales } \\
\text { Briceño (Saturnino Gutiérrez, } \\
\text { Juan Francisco Viales y Rafael } \\
\text { Briceño) }\end{array}$ & $75 \%$ \\
\hline 1823 & $\begin{array}{l}8 \text { electores, de los cuales } 6 \text { perte- } \\
\text { necían a los Viales Briceño (An- } \\
\text { tonio Briceño, Blas María Viales, } \\
\text { Manuel Briceño, Juan José Via- } \\
\text { les, Saturnino Gutiérrez y Javier } \\
\text { Gutiérrez). }\end{array}$ & $75 \%$ & $\begin{array}{l}6 \text { elegidos, de los cuales } 3 \text { perte- } \\
\text { necían a los Viales Briceño } \\
\text { (Saturnino Gutiérrez, Juan } \\
\text { Francisco Viales y Juan José } \\
\text { Viales) }\end{array}$ & $50 \%$ \\
\hline 1824 & $\begin{array}{l}9 \text { electores, de los cuales } 6 \text { pertene- } \\
\text { cían a los Viales Briceño (Antonio } \\
\text { Briceño, Manuel Briceño, Javier } \\
\text { Gutiérrez, Cupertino Briceño, Ro- } \\
\text { que Rosales y Toribio Viales) }\end{array}$ & $66 \%$ & $\begin{array}{l}7 \text { elegidos, de los cuales } 3 \text { per- } \\
\text { tenecían a los Viales Briceño } \\
\text { (Manuel Briceño, Toribio Viales } \\
\text { y Javier Gutiérrez) }\end{array}$ & $42 \%$ \\
\hline Promedio & & $52.4 \%$ & & $60 \%$ \\
\hline $\begin{array}{l}\text { Incorpora- } \\
\text { ción } 1824\end{array}$ & $\begin{array}{l}25 \text { firmantes de la incorporación, } \\
\text { de los cuales } 11 \text { pertenecían a los } \\
\text { Briceño Viales }\end{array}$ & $44 \%$ & $\begin{array}{l}\text { (En negrita están representados } \\
\text { los integrantes de la prosapia } \\
\text { Viales Briceño) }\end{array}$ & \\
\hline
\end{tabular}

Fuente: ANCR, Fondo Municipal: Exp 62, 141 y 82. (Rodríguez, 2015: 61-62)

En tal sentido, sus trayectorias políticas y su injerencia económica en la región permiten inferir que este proceso de incorporación fue decidido por una red de poder familiar, representada por la estirpe Viales Briceño, en función de sus intereses económicos-políticos. Este grupo procuraba la protección y estabilidad política que le garantizara; por lo tanto, seguridad económica y su consolidación como élite dominante en la región.

Desde la creación del corregimiento, la alcaldía mayor, y, finalmente, el partido de Nicoya, el pueblo nicoyano como tal adquirirá relevancia 
política por ser el centro político más importante del partido y, más que eso, por una tradición política originada con la llegada de los españoles al Golfo de Nicoya en 1522.

Resulta oportuno destacar que, a partir del 11 de septiembre de 1820 , una vez que se reinstala la constitución de Cádiz, se inicia el establecimiento del nuevo ayuntamiento tal y como lo establece el acta municipal al señalar que “...y para darle su devido cumplimiento se publicaze y juntaze de nuebo: en consecuencia se estableció el Noble Ayuntamiento con los mismos términos que estava en los años de 1813 y 1814" (sic, ANCR, Municipal, 1820: f1). A partir de 1820 entra en función nuevamente el cabildo de Nicoya y se realizan las elecciones para así elegir a los electores y posteriormente a los miembros del cabildo.

Los puestos del cabildo serían ocupados por una élite social, y en el caso de Nicoya, la prosapia Briceño Viales mantuvo una hegemonía desde la fundación del ayuntamiento en 1813 hasta 1824 , incluso tendiendo un preponderancia hasta 1848. Durante dicho periodo ocupó un $70 \%$ de los principales puestos del cabildo (Rodríguez, 2012: 144).

Del cuadro 4, es plausible evidenciar la hegemonía que tuvieron como electores y o electos en el cabildo de 1820 a 1824, incluso hasta 1848 . Por tal razón, su injerencia y hegemonía como grupo social pudo sopesar, por lo que el capital social (prestigio familiar) fue fundamental. La mejor evidencia de su importancia fue, precisamente, la obtención de los principales cargos políticos, en este caso, a través del cabildo.

Finalmente, es probable que la familia Briceño Viales se convirtiera en la élite social más importante en la región de Nicoya y Santa Cruz hasta mediados del siglo XIX. Aunque no era la única familia poderosa, su acceso a los puestos del cabildo desde 1813, le permitió convertirse en el abolengo más representativo en el ayuntamiento nicoyano.

\section{$X$}

En resumidas cuentas, el proceso de incorporación fue un acontecimiento que marcó indudablemente, no sólo la historia de Costa Rica, sino también, la del territorio del partido de Nicoya. En este lugar se manifestó la injerencia de una red de poder representada por una familia en especial, los Viales Briceño, a los cuales su poderío económico y, principalmente, político les permitió ser la élite local gobernante.

Las cofradías también fueron instituciones utilizadas por la prosapia Briceño Viales, ya que, además de la vinculación religiosa, se convirtieron en una vía de proyección social hacia la comunidad, permitiéndoles interactuar con otros grupos. Así, el vínculo religioso les permitió también obtener beneficios económicos al aprovechar los censos y arrendamientos, permitiéndoles obtener réditos importantes, ya que la administración de los bienes incluía hatos, caballerías, ganado, entre otros tipos de riqueza.

Las capellanías pudieron cumplir un papel relevante, ya que su creación obedecía principalmente a la idea de buscar la salvación de las almas por medio de la celebración de un número determinado de misas a nombre del fundador; así como, también financiar los estudios del sacerdocio de algún miembro familiar o allegado.

La familia Briceño Viales, como élite local, posiblemente logró prestigio social por medio de las milicias. Desde mediados del siglo XVIII los rangos militares serían una constante en la familia, desde el coronel, máximo rango militar, hasta sargentos, tenientes, capitanes y cabos. Al mismo tiempo, es posible que aprovecharan muy bien su prestigio social y su legitimidad para asumir los principales puestos políticos del cabildo de Nicoya.

La decisión de incorporarse pudo haber sido tomada por un grupo que conocía muy bien las ventajas que podría ofrecerle Costa Rica. El "cabildo abierto" fue una reunión para decidir el futuro, no de una región o pueblo, sino de una familia y sus redes de solidaridad, la cual pretendía acrecentar sus intereses económicos, políticos y sociales. 
Del mismo modo, se configuró una élite de poder local claramente definida, ya que una cantidad importante de los puestos políticos del ayuntamiento de Nicoya fueron asumidos por el linaje Briceño Viales de 1813 a 1848.

Finalmente, la participación de la familia Briceño Viales en el proceso de incorporación del partido de Nicoya fue significativa. De manera tal, que su injerencia en la toma de decisiones pudo ser imprescindible, debido a que estaban en juego sus intereses económicos, sociales y hasta políticos. Estos se habían configurado desde mediados del siglo XVIII y habían tenido su pináculo en la primera mitad del siglo XIX, aunque habría que investigar el papel de dicho linaje posterior a la incorporación y analizar su trascendencia o declive de su poder y explicar sus causas, incluyendo las élites de Santa Cruz y Guanacaste.

\section{Fuentes Primarias}

\section{Municipal}

Exp. 439 (1813)

Exp. 62 (1820-1821)

Exp. 141 (1821-1822)

Exp. 82 (1823-1824)

Exp. $309(1831)$

Exp. 12708 (1832)

Exp. 508 (1834)

\section{Protocolos coloniales de Guanacaste}

Exp. 140 (1768)

Exp. 144 (1772)

Exp. 174 (1791)

Exp. $176(1792)$

Exp. $184(1795)$

Exp. 188 (1796)

Exp. 205 (1803)

Exp. 206 (1805)

Exp. 212 (1809-10)

Exp. 225 (1817)

Exp. 227 (1819)

Exp. $228(1820)$

Exp. $232(1822)$

Exp. 243 (1826)

Exp. 248 (1827)

Exp. 250 (1828)
Exp. $274(1832)$

Exp. $292(1835)$

Exp. $310(1838)$

Exp. $334(1842)$

Exp. 353 (1844-45).

Gobernación

Exp. 8845 (1824)

\section{Referencias bibliográficas}

Arguedas, Aaron (2006). The Kingdom of Guatemala: Under the Military Reform 1755-1808. (Tesis Doctoral, Texas, Christian University).

Buska, Soili (2006). Marimba por ti me muero" Region and nation in Costa Rica, 1824-1939. (Thesis for the degree Doctor of Philosophy in the Departament of History Indiana University).

Bertrand, Michel (1998). Las redes de sociabilidad en la Nueva España: fundamentos de un modelo familiar en México (siglos XVII-XVII) En, Poder y desviaciones: génesis de una sociedad mestiza en Mesoamérica. Charlotte Arnaud entre otros. México: Siglo veintiuno editores, s.a, de c. v.

CABrera, Víctor Manuel (1924). Guanacaste: libro conmemorativo del Centenario de incorporación del Partido de $\mathrm{Ni}$ coya. San José: Imprenta María v. de Lines.

Edelman, Marc (1998). La lógica del latifundio. Las grandes propiedades del noroeste de Costa Rica desde fines del siglo XIX. San José: Editorial de la Universidad de Costa Rica: Stanford University Press.

Fernández, León (1888). Colección de Documentos para la Historia de Costa Rica. Costa Rica: Imprenta Nacional.

FonsECA, Elizabeth (1997). Costa Rica Colonial: La tierra y el hombre. San José: EDUCA.

FonSECA, Elizabeth (1998). Centroamérica: su historia. San José: FLACSO: EDUCA.

IbArRA, Eugenia (2003). Las sociedades cacicales de Costa Rica (siglo XVI). San José: Editorial de la Universidad de Costa Rica.

JAÉN, Julio César (2000). El Partido de Nicoya y su integración a Costa Rica.San José: EUCR.

Madrigal, Eduardo (2006). Cartago República Urbana. Elites y poderes en la Costa Rica Colonial 1554-1718. Tesis Universidad de Costa Rica, Université Toulouse II-Le Mirail, Sistemas de Estudios de Posgrado. 
Marchena, Juan (1992). Ejército y milicias en el mundo colonial americano. Madrid: Editorial MAPFRE.

Meléndez, Carlos (1974). "La verdad histórica en torno a la anexión del Partido de Nicoya a Costa Rica". "Sesquicentenario de la anexión del Partido de Nicoya a Costa Rica" ANDE: Revista de la Asociación Nacional de Educadores $\mathrm{N}^{\circ}$ 49:101-108.

Obregón, Clotilde (2002). Una historia de valor. San José: Editorial de la Universidad de Costa Rica.

Quirós, Claudia (1998). La era de la encomienda. San José: Editorial de la Universidad de Costa Rica.

RodríguEz, Arnaldo (2012). Un mirada microanalítica sobre la participación de la familia Briceño Viales en el proceso de anexión del partido de Nicoya a Costa Rica (17861824) (Trabajo final de Graduación para obtener el grado de Maestría profesional en Historia, UCR).

Rodríguez, Arnaldo (2014). Una familia de pode en el partido de Nicoya: el linaje Briceño Viales. En: Núñez, Rodolfo y Marín, Juan José (2014). Guanacaste Vive: La Historia de Guanacaste en el marco del desarrollo socio-regional 1820-2012. San José: Editorial nuevas Perspectivas-Coopeguanacaste.
RODRÍGUEZ, Arnaldo (2014). Linajes poderosos, redes de sociabilidad y poder local en el proceso de anexión del partido de Nicoya a Costa Rica 1786-1824. Ponencia presentada en Berlín, en el XVII Congreso Internacional de AHILA, del 3 al 9 de septiembre. No publicada.

RODRÍGUEZ, Arnaldo (2015). La incorporación del partido de Nicoya a Costa Rica: una supuesta autonomía en un proceso de larga duración (1787-1858). Recuperado de http://www.revistas.una.ac.cr/index.php/perspectivas/ article/view/6750

SibajA, Luis Fernando y Zelaya, Chester (1980). La anexión de Nicoya. San José: EUNED, Segunda Edición.

Solórzano, Juan Carlos y Quirós, Claudia (2006). Costa Rica en el siglo XVI. San José: Editorial UCR.

Velásquez, Carmela (2005). Diccionario de términos coloniales. San José: Editorial de la Universidad de Costa Rica: Asociación Pro-Historia centroamericana.

Velázquez, Carmela (2008). "La educación formal del clero secular en la Diócesis de Nicaragua y Costa Rica". En, Revista electrónica de Historia Número Especial de Diálogos, IX Congreso Centroamericano de Historia: 668-689. 